\title{
Damage caused to varieties of faba bean and lupines by Arion rufus (Linnaeus) and Deroceras reticulatum (O.F. Müller)
}

\author{
Uszkodzenia odmian bobiku i łubinów powodowane \\ przez Arion rufus (Linnaeus) i Deroceras reticulatum (O.F. Müller)
}

\author{
Jan Kozłowski*, Monika Jaskulska
}

\begin{abstract}
Summary
Experiments were carried out in controlled conditions on plants at the 3-4 leaf stage. Three varieties of faba bean, narrow-leafed lupin and yellow lupin included in the studies were exposed to Arion rufus and Deroceras reticulatum feeding. Chinese cabbage and oilseed rape plants were used as controls. In no-choice tests the degree of plant damage was determined on a five-point scale. The results showed that both slug species preferred plants of Sonet yellow lupin, while the least damage was done to Mirela narrow-leafed lupin. The degree of damage to the other plants varied depending on the species of slug. The varieties were identified as less or more susceptible to damage by the studied slug species. The results will serve as an important element in selecting plant varieties for cultivation in areas with dense slug population posing high threat to plants.
\end{abstract}

Key words: Arion rufus; Deroceras reticulatum; varieties; faba bean; lupine; damages

\author{
Streszczenie \\ zagrożonych przez ślimaki. \\ Instytut Ochrony Roślin - Państwowy Instytut Badawczy \\ Zakład Zoologii \\ Władysława Węgorka 20, 60-318 Poznań \\ *corresponding author: j.kozlowski@iorpib.poznan.pl
}

Badania wykonano w kontrolowanych warunkach, na roślinach w fazach rozwojowych 3-4 liści. Obiektem doświadczeń były trzy odmiany bobiku, łubinu wąskolistnego i łubinu żółtego, które eksponowano na żerowanie Arion rufus i Deroceras reticulatum. Roślinami porównawczymi były kapusta pekińska i rzepak oleisty. W testach bez wyboru określono stopień uszkodzenia roślin według 5-stopniowej skali. W wyniku przeprowadzonych testów stwierdzono, że obydwa gatunki ślimaków preferowały rośliny łubinu żółtego Sonet, a najsłabiej uszkadzane były rośliny łubinu wąskolistnego odmiany Mirela. Stopień uszkodzenia pozostałych roślin był zróżnicowany dla poszczególnych gatunków ślimaków. Wyodrębniono odmiany mniej lub bardziej podatne na uszkodzenia przez badane gatunki ślimaków. Uzyskane wyniki będą jednym z ważnych elementów doboru odmian roślin uprawnych w obszarach

Słowa kluczowe: Arion rufus; Deroceras reticulatum; odmiany; bobik; łubin; uszkodzenia 


\section{Wstęp / Introduction}

Rośliny strączkowe uszkadzane są przez wiele gatunków agrofagów. Wśród nich ważną grupą szkodników są ślimaki nagie z rodzin Arionidae i Agriolimacidae. Wyrządzają one znaczne szkody w uprawach różnych gatunków roślin strączkowych, zwłaszcza w bobiku i łubinie. Z uwagi na różne preferencje pokarmowe ślimaków uszkodzenia poszczególnych odmian roślin mogą być silnie zróżnicowane (Hanley i wsp. 1995; Cook i wsp. 1996; Byers 2002; Kozłowski i Kozłowska 2009). Z dotychczasowych obserwacji wynika, że najbardziej narażone na uszkodzenia są rośliny bezpośrednio po wschodach i w fazie rozwoju pierwszych liści (Hanley i wsp. 1995).

Celem przeprowadzonych badań była ocena podatności odmian bobiku i łubinów na żerowanie i uszkodzenia przez ślimaki Arion rufus i Deroceras reticulatum, które obok ślimaka $A$. vulgaris stwarzają największe zagrożenie dla roślin uprawnych.

\section{Materiały i metody / Materials and methods}

Ślimaki użyte w badaniach pochodziły $\mathrm{z}$ populacji występujących w ogrodach w okolicy Poznania i Wronek. Zebrane wiosną 2013 roku młode osobniki ślimaków hodowano $\mathrm{w}$ temperaturze $16^{\circ} \mathrm{C}$, w pojemnikach wyłożonych $5 \mathrm{~cm}$ warstwą ziemi. Dieta ślimaków zawierała: liście kapusty, bulwy ziemniaków, korzenie marchwi oraz otręby pszenne $\mathrm{z}$ dodatkiem węglanu wapnia, które wymieniano, co trzy dni. Przed rozpoczęciem testów ślimaki przez 48 godzin głodzono. Rośliny w fazie 3-4 liści właściwych uzyskano z nasion w szklarni Instytutu Ochrony Roślin Państwowego Instytutu Badawczego w Poznaniu.

Testy bez wyboru na roślinach trzech odmian łubinu wąskolistnego, łubinu żółtego i bobiku, które eksponowano na żerowanie ślinika wielkiego - A. rufus i pomrowika plamistego $-D$. reticulatum, wykonano w kabinie klimatycznej w temperaturze $17^{\circ} \mathrm{C}$, wilgotności powietrza $(\mathrm{RH}-$ relative humidity) $73 \pm 3 \%$ i długości dnia 12 godzin. Roślinami porównawczymi były kapusta pekińska i rzepak oleisty. Przed przystąpieniem do testów, w plastikowych, zamykanych pojemnikach $(26 \times 26 \times 14 \mathrm{~cm})$, zaopatrzonych w otwory wentylacyjne, posadzono w gliniastopróchnicznej ziemi po pięć roślin $\mathrm{w}$ fazie 3-4 liści poszczególnych gatunków i odmian. Po dwóch dniach w każdym pojemniku umieszczono po jednym osobniku ślimaka o średniej masie: A. rufus $-1,30 \mathrm{~g}$ i D. reticulatum - 0,34 g. Obserwacje prowadzono, co dwa dni, określając stopień uszkodzenia roślin według pięciostopniowej skali (0 - brak uszkodzeń; 25; 50; 75 i 100\% uszkodzonej powierzchni roślin). Dla każdego badanego gatunku i odmiany rośliny wykonano po pięć powtórzeń. Uzyskane wyniki obserwacji poddano analizie wariancji i zastosowano test Fishera przy poziomie istotności $\alpha=0,05$.

\section{Wyniki i dyskusja / Results and discussion}

Istotne różnice w wielkościach uszkodzeń roślin wystąpiły już po 24 godzinach żerowania obydwu gatunków ślimaków. A. rufus najsilniej uszkadzał rośliny kapusty pekińskiej odmiany Hilton i łubinu żółtego odmiany Dukat (26-27\%). Najsłabiej uszkodzone były rośliny łubinu wąskolistnego odmiany Mirela $(<10 \%)$ (tab. 1). Od piątego dnia silnie uszkodzone były także rośliny łubinu wąskolistnego odmiany Regent. Po siedmiu dniach istotnie najsilniej uszkodzone były rośliny łubinu wąskolistnego odmiany Regent i łubinu żółtego odmiany Dukat (94\%), a najsłabiej łubinu wąskolistnego odmiany Mirela i rzepaku oleistego odmiany Bazyl. Po dziewięciu dniac w 100\% zostały uszkodzone rośliny łubinu wąskolistnego odmiany: Regent i Sonet, łubinu żółtego odmiany Parys oraz bobiku odmiany Bobas i Granit.

Wielkość uszkodzeń roślin po jednym dniu żerowania D. reticulatum wahała się od $3 \%$ dla bobiku odmiany Olga do $19 \%$ dla kapusty pekińskiej odmiany Hilton i łubinu wąskolistnego odmiany Sonet (tab. 2). Po tygodniu roślinami silnie uszkodzonymi były kapusta pekińska i rzepak oleisty, a najsłabiej uszkodzony był bobik odmiany Olga i łubin wąskolistny odmiany Mirela. Tendencja ta utrzymywała się do ostatniego, 17. dnia obserwacji. W tym dniu uszkodzenie roślin kapusty pekińskiej i rzepaku ozimego było największe (>92\%), a istotnie słabiej uszkodzone były rośliny bobiku odmiany Olga i Granit (44-48\%) oraz łubinu wąskolistnego odmiany Mirela (51\%).

Łączna analiza wyników wykazała, że stopień uszkodzenia niektórych roślin przez obydwa gatunki ślimaków był podobny (tab. 3). Stwierdzono, że $A$. rufus i $D$. reticulatum preferują kapustę pekińską odmiany Hilton i łubin wąskolistny odmiany Sonet, natomiast słabo akceptowany jest łubin wąskolistny odmiany Mirella. Wyniki wcześniejszych badań wskazują, że kapusta pekińska należy do roślin preferowanych przez większość gatunków ślimaków (Port i Ester 2002). Przyczyną słabych uszkodzeń łubinu wąskolistnego odmiany Mirela była prawdopodobnie wysoka zawartość alkaloidów (> 1,3\% suchej masy), które mogą ograniczać żerowanie ślimaków na roślinach (Aguiar i Wink 1999; Chevalier i wsp. 2000). Podobne wyniki dotyczące niskiej podatności łubinu odmiany Mirela na uszkodzenia stwierdzono w przypadku ślimaka A. vulgaris (Kozłowski i wsp. 2013).

Stwierdzono również, że stopień uszkodzenia niektórych roślin różnił się istotnie dla poszczególnych gatunków ślimaków (tab. 3). Silnie uszkadzane przez A. rufus - łubin żółty odmiany Dukat i łubin wąskolistny odmiany Regent były słabiej uszkadzane przez $D$. reticulatum, natomiast słabo uszkadzany przez $D$. reticulatum bobik odmiany Olga był silnie uszkadzany przez $A$. rufus. Potwierdza to wcześniejsze informacje dotyczące zróżnicowanej preferencji pokarmowej poszczególnych gatunków ślimaków w stosunku do niektórych gatunków i odmian roślin (Hanley i wsp. 1995; Cook i wsp. 1996; Kozłowski i Kozłowska 2009).

Masa użytych w testach ślimaków $A$. rufus była czterokrotnie wyższa niż $D$. reticulatum, co spowodowało znaczne różnice $\mathrm{w}$ tempie ich żerowania i uszkodzeń roślin. A. rufus uszkadzał niektóre rośliny w $100 \%$ już po 9 dniach żerowania, natomiast $D$. reticulatum po 17 dniach. Dorosłe osobniki $A$. rufus osiągają długość $14 \mathrm{~cm}$, natomiast $D$. reticulatum $4,5 \mathrm{~cm}$, a ich wielkość ma istotny wpływ na tempo powstawania uszkodzeń roślin. 
Tabela 1. Tempo i wielkość uszkodzeń roślin przez A. rufus i wyniki testu Fischera przy poziomie istotności $\alpha=0,05$

Table 1. Rate and size of damages to plants caused by A. rufus and results of Fisher's test with $\alpha=0.05$

\begin{tabular}{l|c|c|c|c|c}
\hline \multirow{2}{*}{$\begin{array}{c}\text { Gatunek rośliny i (odmiana) } \\
\text { Species of plants and (cultivar) }\end{array}$} & \multicolumn{4}{|c}{ Dni żerowania ślimaków - Days of slug feeding } \\
\cline { 2 - 6 } & 1 & 3 & 5 & 7 & 9 \\
\hline Bobik (Bobas) - Vicia faba & $20,0 \mathrm{bc}$ & $41,0 \mathrm{bc}$ & $73,0 \mathrm{~cd}$ & $90,0 \mathrm{bcd}$ & 100,0 \\
\hline Bobik (Granit) - V.faba & $17,0 \mathrm{abc}$ & $35,0 \mathrm{abc}$ & $73,0 \mathrm{~cd}$ & $88,0 \mathrm{bcd}$ & 100,0 \\
\hline Bobik (Olga) - V.faba & $19,0 \mathrm{bc}$ & $37,0 \mathrm{abc}$ & $64,0 \mathrm{bc}$ & $82,0 \mathrm{bc}$ & 96,0 \\
\hline Lubin wąskolistny (Mirela) - Lupinus angustifolius & $9,0 \mathrm{a}$ & $23,0 \mathrm{a}$ & $37,0 \mathrm{a}$ & $60,0 \mathrm{a}$ & 83,0 \\
\hline Lubin wąskolistny (Regent) - L. angustifolius & $21,0 \mathrm{bc}$ & $41,0 \mathrm{bc}$ & $84,0 \mathrm{~d}$ & $99,0 \mathrm{~d}$ & 100,0 \\
\hline Lubin wąskolistny (Sonet) - L. angustifolius & $22,0 \mathrm{bc}$ & $44,0 \mathrm{bc}$ & $78,0 \mathrm{~cd}$ & $91,0 \mathrm{~cd}$ & 100,0 \\
\hline Lubin żółty (Dukat) - L. luteus & $26,0 \mathrm{c}$ & $47,0 \mathrm{c}$ & $80,0 \mathrm{~d}$ & $94,0 \mathrm{~cd}$ & 99,0 \\
\hline Lubin żółty (Mister) - L. luteus & $21,0 \mathrm{bc}$ & $44,0 \mathrm{bc}$ & $71,0 \mathrm{~cd}$ & $88,0 \mathrm{bcd}$ & 94,0 \\
\hline Lubin żółty (Parys) - L. luteus & $16,0 \mathrm{abc}$ & $33,0 \mathrm{abc}$ & $69,0 \mathrm{~cd}$ & $87,0 \mathrm{bc}$ & 100,0 \\
\hline Kapusta pekińska (Hilton) - Brassica pekinensis & $27,0 \mathrm{c}$ & $46,0 \mathrm{c}$ & $78,0 \mathrm{~cd}$ & $85,0 \mathrm{bc}$ & 88,0 \\
\hline Rzepak ozimy (Bazyl) - B. napus & $14,0 \mathrm{ab}$ & $34,0 \mathrm{abc}$ & $53,0 \mathrm{~b}$ & $77,0 \mathrm{~b}$ & 90,0 \\
\hline
\end{tabular}

Wartości w kolumnach oznaczone tą samą literą nie różnią się istotnie - Values in columns marked with the same letters do not differ significantly

Tabela 2. Tempo i wielkość uszkodzeń roślin przez D. reticulatum i wyniki testu Fischera przy poziomie istotności $\alpha=0,05$

Table 2. Rate and size of damages to plants caused by D. reticulatum and results of Fisher's test with $\alpha=0.05$

\begin{tabular}{|c|c|c|c|c|c|c|c|c|c|}
\hline \multirow{2}{*}{$\begin{array}{c}\text { Gatunek rośliny i (odmiana) } \\
\text { Species of plants and (cultivar) }\end{array}$} & \multicolumn{9}{|c|}{ Dni żerowania ślimaków na roślinach - Days of slug feeding } \\
\hline & 1 & 3 & 5 & 7 & 9 & 11 & 13 & 15 & 17 \\
\hline Bobik (Bobas) - Vicia faba & $9,0 \mathrm{abc}$ & $12,0 \mathrm{abc}$ & 18,0 abcd & 21,0 abcd & $28,0 \mathrm{abc}$ & $38,0 \mathrm{abc}$ & $41,0 \mathrm{ab}$ & 47,0 abcd & $58,0 \mathrm{abc}$ \\
\hline Bobik (Granit) $-V . f a b a$ & $5,0 \mathrm{ab}$ & $13,0 \mathrm{bc}$ & 23,0 bcd & 32,0 cdef & 35,0 bcd & $39,0 \mathrm{abc}$ & $42,0 \mathrm{ab}$ & $46,0 \mathrm{ab}$ & $48,0 \mathrm{a}$ \\
\hline Bobik (Olga) $-V . f a b a$ & $3,0 \mathrm{a}$ & $3,0 \mathrm{a}$ & $6,0 \mathrm{a}$ & $8,0 \mathrm{a}$ & $16,0 \mathrm{a}$ & $20,0 \mathrm{a}$ & $25,0 \mathrm{a}$ & $32,0 \mathrm{a}$ & $44,0 \mathrm{a}$ \\
\hline $\begin{array}{l}\text { Lubin wąskolistny (Mir } \\
\text { Lupinus angustifolius }\end{array}$ & $10,0 \mathrm{abc}$ & $9,0 \mathrm{ab}$ & $13,0 \mathrm{ab}$ & $17,0 \mathrm{ab}$ & $19,0 \mathrm{ab}$ & $20,0 \mathrm{a}$ & $25,0 \mathrm{a}$ & $39,0 \mathrm{ab}$ & 51,0 al \\
\hline $\begin{array}{l}\text { Łubin wąskolistny (Regent) - } \\
\text { L. angustifolius }\end{array}$ & $11,0 \mathrm{abc}$ & $15,0 \mathrm{bc}$ & $25,0 \mathrm{bcd}$ & 31,0 bcdef & $42,0 \mathrm{~cd}$ & $49,0 \mathrm{bcd}$ & $57,0 \mathrm{bc}$ & $65,0 \mathrm{~d}$ & $77,0 \mathrm{c}$ \\
\hline $\begin{array}{l}\text { Lubin wąskolistny (Sonet) - } \\
\text { L. angustifolius }\end{array}$ & $18,0 \mathrm{c}$ & 26,0 de & 32,0 de & $35,0 \mathrm{def}$ & $41,0 \mathrm{~cd}$ & $47,0 \mathrm{bcd}$ & $51,0 \mathrm{~b}$ & $64,0 \mathrm{~cd}$ & 79,0 de \\
\hline Łubin żółty (Dukat) - L. luteus & 11,0 abc & $14,0 \mathrm{bc}$ & 19,0 abcd & 25,0 bcde & $31,0 \mathrm{abc}$ & $39,0 \mathrm{abc}$ & $50,0 \mathrm{~b}$ & $63,0 \mathrm{~cd}$ & $78,0 \mathrm{~d}$ \\
\hline Łubin żółty (Mister) - L. luteus & $10,0 \mathrm{abc}$ & $16,0 \mathrm{bc}$ & $22,0 \mathrm{bcd}$ & 23,0 bcde & $27,0 \mathrm{abc}$ & $32,0 \mathrm{ab}$ & $40,0 \mathrm{ab}$ & $60,0 \mathrm{~cd}$ & 73,0 \\
\hline Łubin żółty (Parys) - L. luteus & $4,0 \mathrm{ab}$ & $11,0 \mathrm{abc}$ & $15,0 \mathrm{abc}$ & $18,0 \mathrm{abc}$ & $23,0 \mathrm{abc}$ & $37,0 \mathrm{abc}$ & $41,0 \mathrm{ab}$ & $53,0 \mathrm{bcd}$ & $68,0 \mathrm{bc}$ \\
\hline $\begin{array}{l}\text { Kapusta pekińska (Hilton) - } \\
\text { Brassica pekinensis }\end{array}$ & $19,0 \mathrm{c}$ & $32,0 \mathrm{e}$ & $41,0 \mathrm{e}$ & $45,0 \mathrm{f}$ & $54,0 \mathrm{~d}$ & $66,0 \mathrm{~d}$ & $76,0 \mathrm{~d}$ & $94,0 \mathrm{e}$ & $99,0 \mathrm{f}$ \\
\hline $\begin{array}{l}\text { Rzepak ozimy (Bazyl) - } \\
\text { B. napus }\end{array}$ & $14,0 \mathrm{bc}$ & $19,0 \mathrm{~cd}$ & 29,0 cde & 36,0 ef & $50,0 \mathrm{~cd}$ & $55,0 \mathrm{~cd}$ & $72,0 \mathrm{~cd}$ & $88,0 \mathrm{e}$ & 93,0 ef \\
\hline
\end{tabular}

Wartości w kolumnach oznaczone tą samą literą nie różnią się istotnie - Values in columns marked with the same letters do not differ significantly

Tabela 3. Stopień uszkodzenia roślin przez A. rufus i D. reticulatum

Table 3. Degree of damage to plants caused by A. rufus and D. reticulatum

\begin{tabular}{l|c|c}
\hline \multicolumn{1}{c|}{ Gatunek rośliny i (odmiana) - Species of plants and (cultivar) } & A. rufus & D. reticulatum \\
\hline \multicolumn{1}{c|}{1} & 2 & 3 \\
\hline Bobik (Bobas) - Vicia faba & + & $\mathrm{x}$ \\
\hline Bobik (Granit) - V.faba & + & $\mathrm{xx}$ \\
\hline Bobik (Olga) - V.faba & $\mathrm{xx}$ & $\mathrm{xx}$ \\
\hline Lubin wąskolistny (Mirela) - Lupinus angustifolius & ++ & $*$ \\
\hline Łubin wąskolistny (Regent) - L. angustifolius & + & $*$ \\
\hline Lubin wąskolistny (Sonet) - L. angustifolius & ++ & $*$ \\
\hline Lubin żółty (Dukat) - L. luteus & + & $*$
\end{tabular}




\begin{tabular}{l|c|c}
\hline \multicolumn{1}{c|}{1} & 2 & 3 \\
\hline Lubin żółty (Parys) - L. luteus & $*$ & $*$ \\
\hline Kapusta pekińska (Hilton) - Brassica pekinensis & ++ & ++ \\
\hline Rzepak ozimy (Bazyl) - B. napus & $\mathrm{x}$ & + \\
\hline
\end{tabular}

$\mathrm{xx}$ - najsłabiej uszkadzane - least damaged; $\mathrm{x}$ - słabo uszkadzane - lightly damaged

++ - bardzo silnie uszkadzane - most heavily damaged; + - silnie uszkadzane - heavily damaged

* - średnio uszkadzane - average damaged

\section{Wnioski / Conclusions}

1. Podatność niektórych odmian łubinu i bobiku na uszkodzenia przez A. rufus i D. reticulatum jest zróżnicowana, co wynika $\mathrm{z}$ różnic $\mathrm{w}$ składzie chemicznym tych roślin i różnych wymagań pokarmowych ślimaków.
2. Odmiany łubinu wąskolistnego charakteryzujące się wysoką zawartością alkaloidów (odmiana Mirela) są słabo uszkadzane przez ślimaki.

3. Na powierzchniach zasiedlonych przez A. rufus należy unikać uprawy łubinów wąskolistnych odmian Regent, Sonet oraz łubinu żółtego odmiany Dukat z uwagi na ich wysoką podatność na żerowanie i uszkodzenia przez tego ślimaka.

\section{Literatura / References}

Aguiar R., Wink M. 1999. Mollusc-deterrent avtivity of lupin alkaloids. p. 97-98. In: Procceding 9th International Lupin Conference. Klink/Mültriz, International Lupin Association, New Zeeland, Canterbury, 20-24 June 1999, 481 pp.

Byers R.A. 2002. Agriolimacidae and Arionidae as pests in lucerne and other legumes in forage systems of north-eastern North America. p. 325-335. In: "Molluscs as Crop Pests" (G.M. Barker, ed.). Landcare Research Hamilton, New Zealand. CABI Publishing, UK, 468 pp.

Chevalier L., Desbuquois C., Papineau J., Charrier M. 2000. Influence of the quinolizidine alkaloid content of Lupinus albus (Fabaceae) on the feeding choice of Helix aspersa (Gastropoda: Pulmonata). Journal of Molluscan Studies 66: 61-68.

Cook R.T., Bailey S.E.R., McCrohan C.R. 1996. Slug preference for winter wheat cultivars and common agricultural weeds. Journal of Applied Ecology 33 (4): 866-872.

Hanley M.E., Fenner M., Edwards P.J. 1995. The effect of seedling age on the likelihood of herbivory by the slug Deroceras reticulatum. Functional Ecology 9: 754-759.

Kozłowski J., Jaskulska M., Kozłowska M. 2013. Porównanie uszkodzeń różnych gatunków roślin upraw małoobszarowych powodowanych przez ślimaka Arion lusitanicus Mabille. [The comparison of damage caused by the slug Arion lusitanicus Mabille to diferrent plant species of small-area crops]. Progress in Plant Protection/Postępy w Ochronie Roślin 53 (4): 831-834.

Kozłowski J., Kozłowska M. 2009. Palatability and consumption of 95 species of herbaceous plants and oilseed rape for Arion lusitanicus Mabille, 1868. Journal of Conchology 40 (1): 79-90.

Port R., Ester A. 2002. Gastropods as pests in vegetables and ornamental crops in Western Europe. p. 337-352. In: "Molluscs as Crop Pests" (G.M. Barker, ed.). Landcare Research Hamilton, New Zealand. CABI Publishing, UK, 468 pp. 